\title{
Research of Air Traffic Control Students Proportion Concerning Their Attitude to Risk
}

\author{
O.M. Reva \& S.P. Borsuk \\ National aviation university, Kiev, Ukraine
}

\begin{abstract}
Modern air traffic control system consists of entities of different types. Their list includes front line operators, software, hardware, norms and conditions etc. Norms and conditions of air traffic control as part of entire process are changed according to balance in requirements of safety and efficiency. It is important for those changes to take into account many important process properties and parameters. One of those properties is front line operators personal attitude to risky situations.
\end{abstract}

KEYWORD: human factor, flight safety; air traffic control; education; flight norms violation; usefulness functions.

\section{RESEARCH AREA}

\subsection{Introduction}

Modern norms of air traffic control (ATC), in particular flight level norms on different stages of flight, are changed along with air space exploitation rules and modernization of flight process participants interaction due to air traffic management (ATM) efficiency requirements increase. Flight level norms changes are based on officially implemented documents that usually ignore some special psychophysiological properties of air traffic controllers perception of ATC components. This may cause increase of potentially harmful situation probability that is unacceptable for civil aviation.

\subsection{Urgency}

Taking into account how important human factor is concerning flight safety (FS) wide number of researches are held for a long time including those about psycho-physiological peculiarities of operators, namely pilots. However despite the fact that ATC operator are also mentioned as "front line operators" (ICAO 2009), there is a lack of attention to researches of their professional activities. Especially this is dangerous since ATC operators are supporting FS directly. Thus continuous chain of FS supporting means and regulations has some weak links that are up to be discussed. This makes paper topic urgent.

\subsection{Problem statement}

Professional activity of ATC operators goes along with their own thinking process. This process generates some attitude to flight control norms and conditions and may influence solution taking process, thus influencing FS. Since experienced ATC operators usually work on the same working place for a long time, it may influence their opinions. That's why it is important to determine opinions of ATC operator that has no real work experience. This allows to form certain starting point for further researches. The task of this paper is to define ATC students attitude to risk during flight norms violation.

\section{SOLUTION}

\subsection{Method}

To solve stated problem the method of assessment usefulness functions construction was used for functions with limited number of points. This concerns solution of closed decision taking tasks (Keeney and Raiffa1993, Reliability and efficiensy in engeneering 1988) adopted for aviation branch (Reva et al. 1998, Reva et al. 2012, Reva et al. 2014).

Method itself may be described as the following. Participants are proposed to solve professional situation, presented as lottery. Lottery states that participant has $50 \%$ chance for getting distance between aircrafts $S_{0}=0(\mathrm{~km})$ or $S_{1}=S(\mathrm{~km})$ where 
$S$ is current distance norm. In these circumstances participant is proposed to state distance in range $(0, S)$ which he would like to receive with $100 \%$ chance instead of playing lottery. Usefulness of range boarders are equal to $v\left(\mathrm{~S}_{0}\right)=0, v\left(S_{1}\right)=1$. Usefulness of participant's solution is stated to be equal $v\left(\mathrm{~S}_{0.5}\right)=0.5$.

Using received value $S_{0.5}$ two more lottery equivalents are up to be calculated. Procedure of their determination is the same as with first one. First equivalent $S_{0.25}$ is situated between $S_{0}$ and $S_{0.5}$ equivalents. Second equivalent $S_{0.75}$ is situated between $S_{0.5}$ and $S_{1}$ equivalents. Respondents are proposed to determine distance value $S_{0.25}$ that would be more preferable than randomly accepting distance $S_{0}$ or $S_{0.5}$ with $50 \%$ probability and distance value $S_{0.75}$ that would be more preferable than randomly accepting distance $S_{0.5}$ or $S_{1}$ with $50 \%$ probability. Composition of these five points $\left(S_{0}, S_{0.25}, S_{0.5}, S_{0.75}, S_{1}\right)$ is a key for usefulness-safety function construction. Such function could be used for air traffic norms research for distances between the aircrafts.

Research involved 132 students of "Air traffic control" specialty in National aviation university (Kiev) and Kirovohrad flight academy (Kirovohrad). All those students had no licenses. They all had about 150-200 hours of practical radar simulator experience and 4-5 years of studying ATC-related subjects (depending on year of study). Lottery task was given as open test with three fields for lottery equivalents. Current testing was part of wider research. Taking into account all questions we may assume that students had approximately one minute for a single equivalent calculation. All students were informed that polling results will not influence their grades at the end of semester.

\subsection{Research results}

Polling included following different flight level norms:

- $8 \mathrm{~km}$ Radar horizontal separation minima, which are connected with wake Turbulence Heavy aircraft $(\mathrm{H})$ follows Heavy aircraft $(\mathrm{H})$

- $12 \mathrm{~km}$ Radar horizontal separation minima, which are connected with wake Turbulence Light aircraft (L) follows Heavy aircraft $(\mathrm{H})$

- $30 \mathrm{~km}$ at the moment of crossing on conditions that no tracks converging in ACC (General ATC) (CTA (Control Area)) and APP (local ATC) (TMA (Terminal Control Area)) when crossing the opposite level occupied by another aircraft.
Results of polling answers distribution according to operators attitude to risk are given in the table 1 .

Table 1: Attitude to risk for different distances

\begin{tabular}{|c|c|c|c|c|}
\hline \multirow{2}{*}{$\begin{array}{l}\text { Flight } \\
\text { norm }\end{array}$} & \multicolumn{3}{|c|}{ Attitude to risk, $\mathrm{n}$} & \multirow{2}{*}{$\begin{array}{c}\text { Proportion of } \\
\text { different attitudes } \\
\text { operators }\end{array}$} \\
\hline & $\begin{array}{l}\text { Tends } \\
\text { to risk } \\
\end{array}$ & $\begin{array}{c}\text { Indifferent } \\
\text { to risk }\end{array}$ & $\begin{array}{l}\text { Tends } \\
\text { to safe } \\
\end{array}$ & \\
\hline $8 \mathrm{~km}$ & 3 & 15 & 114 & $\mathrm{~T}: \mathrm{I}: \mathrm{S} \Leftrightarrow 1: 5: 38$ \\
\hline $12 \mathrm{~km}$ & 8 & 12 & 112 & $\mathrm{~T}: \mathrm{I}: \mathrm{S} \Leftrightarrow 1: 1.5: 14$ \\
\hline $30 \mathrm{~km}$ & 5 & 6 & 121 & $\mathrm{~T}: \mathrm{I}: \mathrm{S} \Leftrightarrow 1: 1.2: 24.2$ \\
\hline$\Sigma$ & 16 & 33 & 347 & $\mathrm{~T}: \mathrm{I}: \mathrm{S} \Leftrightarrow 1: 2.06: 21.68$ \\
\hline
\end{tabular}

Hence as a result of research it was found that ATC students has following distribution of indifferent (I), those that tend to risk (T), and those that doesn't tend to safe $(\mathrm{S})$ :

$$
\begin{aligned}
\text { T: I: } \mathrm{S} & \Leftrightarrow 16: 33: 347 \Leftrightarrow 1: 2.06: 21.68 \Leftrightarrow \\
& \Leftrightarrow 4.04 \%: 8.3 \%: 87.6 \%
\end{aligned}
$$

Taking into account (Kozeletskiy 1979, Kamishin and Reva 2012) that intention of playing lottery or taking risk may be observed as consequence of motivation to reach success and intention of avoiding risk may be consequence of avoiding failure - it could be stated that our scientific results witness about students wish to avoid risk during professional activities.

Distribution of respondents opinions for all three norms are show on figures 1-3. Figure 1 shows distribution of respondents opinions about $S_{0.25}$, $S_{0.5}$ and $S_{0.75}$ values for $8 \mathrm{~km}$ norm. Diamond stand for $S_{0.25}$, squares stand for $S_{0.5}$, triangles stands for $S_{0.75}$.

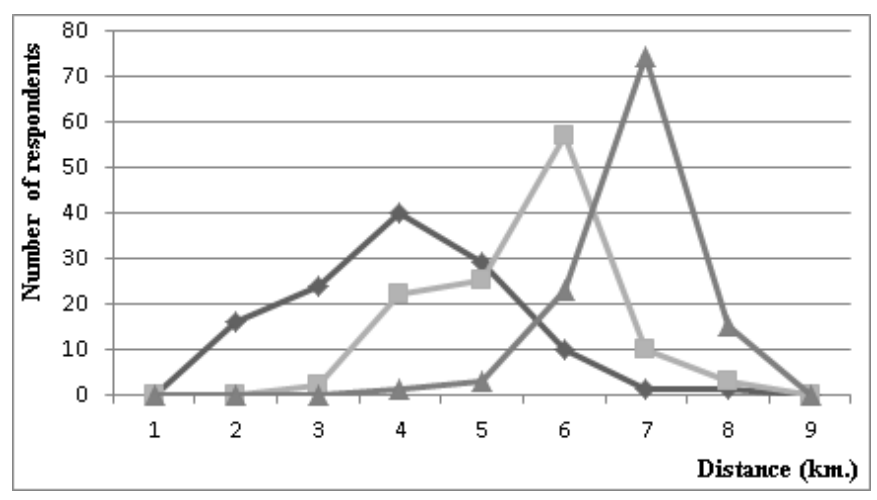

Figure 1: Distribution of respondents opinions about lottery equivalence values for $8 \mathrm{~km}$ norm

Figure 2 shows distribution of respondents opinions about $S_{0.25}, S_{0.5}$ and $S_{0.75}$ values for $12 \mathrm{~km}$ norm. Diamonds stand for $S_{0.25}$, squares stand for $S_{0.5}$, triangles stands for $S_{0.75}$. 


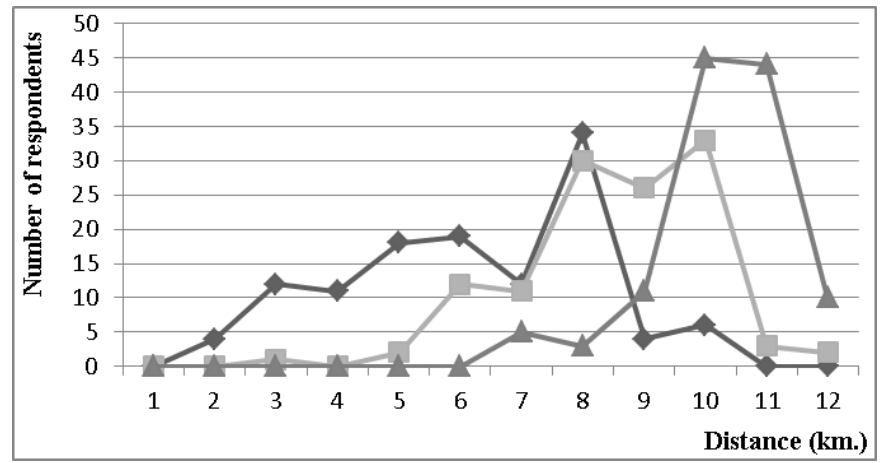

Figure 2: Distribution of respondents opinions about lottery equivalence values for $12 \mathrm{~km}$ norm

Figure 3 shows distribution of respondents opinions about $S_{0.25}, S_{0.5}$ and $S_{0.75}$ values for $30 \mathrm{~km}$ norm. Diamonds stand for $S_{0.25}$, squares stand for $S_{0.5}$, triangles stands for $S_{0.75}$.

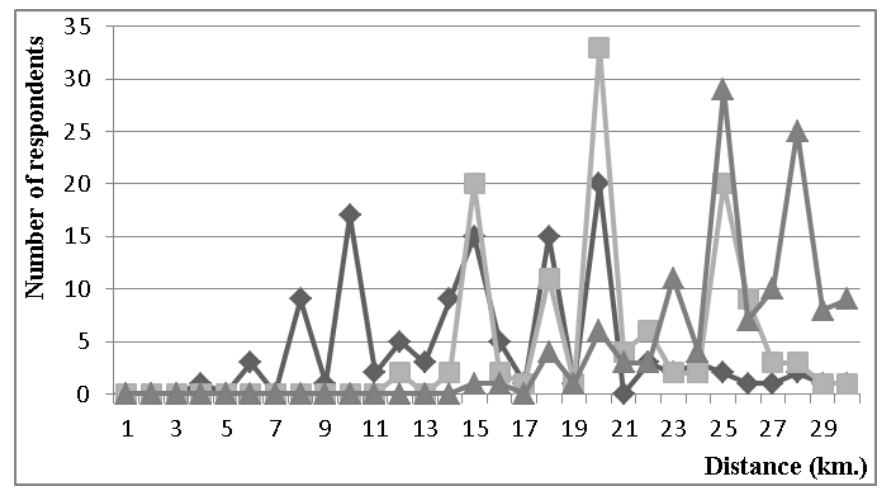

Figure 3: Distribution of respondents opinions about lottery equivalence values for $30 \mathrm{~km}$ norm

Average values of lottery equivalences for all three norms are shown in table 2.

Table 2: Attitude to risk for different distances

\begin{tabular}{|c|c|c|c|}
\hline \multirow{2}{*}{ Flight norm } & \multicolumn{3}{|c|}{ Average values } \\
\cline { 2 - 4 } & $S_{0.25}$ & $S_{0.5}$ & $S_{0.75}$ \\
\hline $8 \mathrm{~km}$ & 4.253968 & 6 & 7.769841 \\
\hline $12 \mathrm{~km}$ & 6.304 & 8.856 & 10.784 \\
\hline $30 \mathrm{~km}$ & 15.84127 & 21.01587 & 25.76984 \\
\hline
\end{tabular}

One more thing that should be noted is that some values chosen by respondents were out or given norms range. For example there are three respondents that stated $S_{1}$ value for $30 \mathrm{~km}$ norm to be equal to 35,36 and 37 . This fact doesn't influence general attitude proportion because belonging of respondent opinion to certain group came out of resultant function graph (Reliability and efficiensy in engeneering, 1988).

Figures 4-6 shows example of first respondent resultant functions for all three norms. Respondent's $\left(S_{0}, S_{0.25}, S_{0.5}, S_{0.75}, S_{1}\right)$ values for $8 \mathrm{~km}$ are $(0,5,6,7$, $8)$, for $12 \mathrm{~km}$ are $(0,8,10,11,12)$, for $30 \mathrm{~km}$ are $(0$, $20,23,28,30)$.

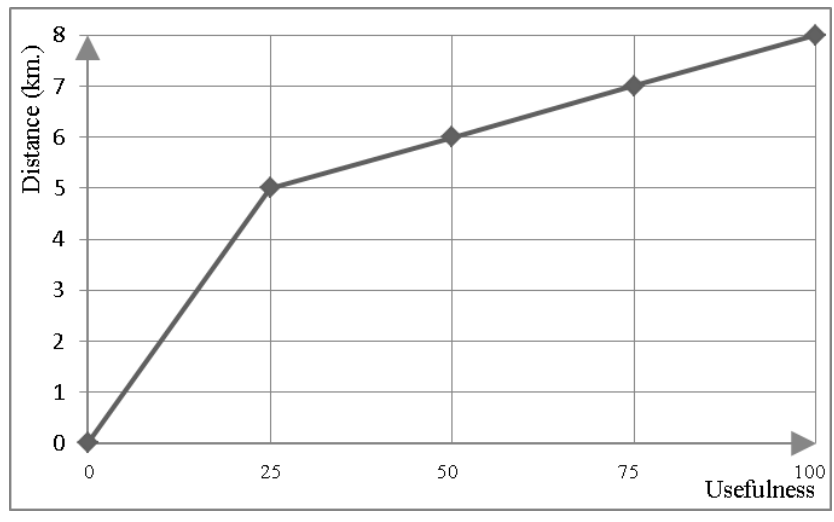

Figure 4: Example of first respondent resultant function for 8 $\mathrm{km}$ norm

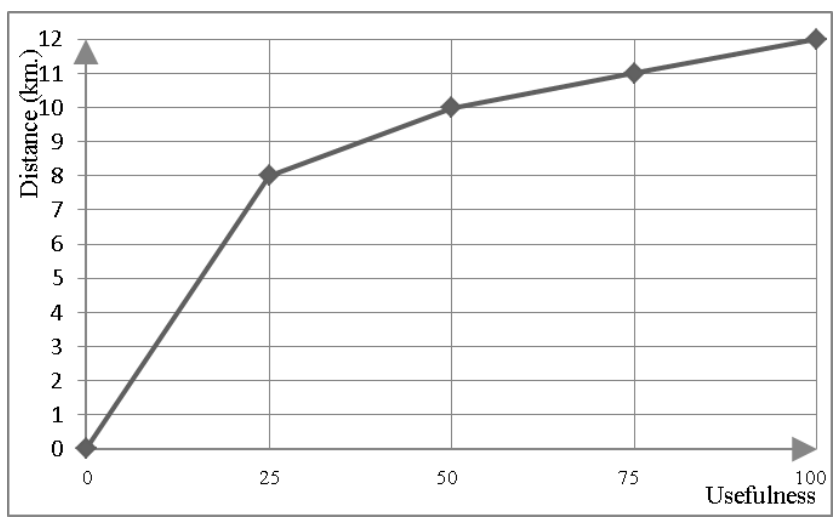

Figure 5: Example of first respondent resultant function for 12 km norm

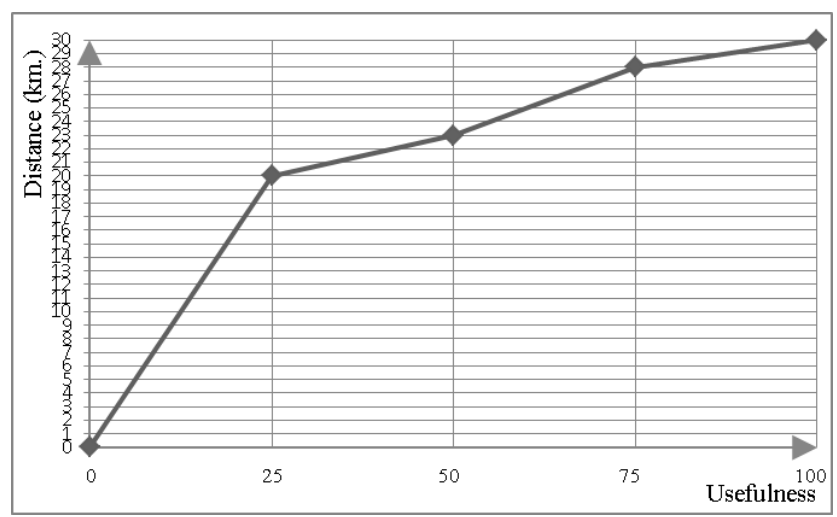

Figure 5: Example of first respondent resultant function for 12 km norm

All function clearly witness about respondent's tendency to safe rather than to risk.

\section{CONCLUSIONS}

Taking into account presented scientific results it is possible to state that majority of ATC students $(87.6 \%)$ tends to be safe of risk that proves their intentions for avoid failures during professional activities.

Another interesting result concerns distances and changes in respondents proportions. Number of students that tends to risk relative to indifferent students number at $8 \mathrm{~km}$ is obviously lower comparing to same values at $12 \mathrm{~km}$ But at $30 \mathrm{~km}$ 
norm number of indifferent students is almost equal to number of risky one's. This result may be caused by different flight conditions although some additional researches are necessary.

Nevertheless received results may be used in the ATC students educational process during correction or development of study program.

\section{REFERENCES}

[1] ICAO, 2009, Safety Management Manual Doc 9859 AN/474,ICAO Montreal,Kanada, 251 pages.

[2] Keeney R.L., Raiffa H., 1993, Decisions with multiple objectives-preferences and value tradeoffs, Cambridge University Press, Cambridge \& New York, 569 pages

[3] Kamisin V.V., Reva O.M., 2012, Methods of system analys in qualimetry of educational-upbringing process: monograph. K.: Informational systems, 270 pages.

[4] Kozeletskiy Y.,1979, Psychological theory of solutions: translated from polish. G.E. Mintz, V.N. Porus; editorshipB.V. Biryukova, M.: Progress, 504 pages.

[5] Reliability and efficiensy in engeneering: Handbook: in 10 volumes. - V.3. Efficiency of technical systems / under general editorship of V.F. Utkin, Y.V. Kryuchkov. - M.: Maschinostroenie, 1988 . - 328 pages.
[6] Reva O.M., Shmelyova T.F.1998, Paradox of air traffic controller activity psychological dominant during stochatic risk. Problems of aicrafts air-navigation systems development, (Air navigation and avionics - 98): materialsof international scientific conference, K.: KIUCA, page. 135.

[7] Reva, O.M., Muhtarov P.S., Korj S.I., Nedbay S.V. 2012, Algorythmization of aviation oprator attitudeto risk definitionprocedure.(Aviation-space devices and technology: sci.-tech. magazine,H.: National airpace ubiversity named aferM.E. Jukovsky «HAI»)№ 1 (88),pages. 109-114.

[8] Reva, A.N.,Muhtarov P.S., Nedbay S.V. 2012, Theoretical model of aviation operator main activities dominantdetermination during risky cinditions.Elmi məcmuələr: Jurnal Milli Aviasiya Akademiyasinin, Baki, Oktyabr-Dekabr., Child № 4., pages 64-73.

[9] Reva O.M., Muhtarov P.S., Mirzoev B.M., Vdovichenko V.V., Nasirov S.S.2014, Dynamics of main decision taking dominance of air traffic controller during activities conditions complications. Modern information and innovation technologiees on transport (MINNT - 2014): materials of VI international scientific practical conference., dedicated to 180-yearsof Herson state sea academy foundation.Herson, 27-29 may 2014, Herson: HDMA, pages 86-89. 